August. In the Greenland Sea ice was less than usual, and parts of the coast of Greenland had periods of accessibility. Twice during May the East Green. land pack touched the north-west coast of Iceland. In Davis Strait the amount of ice was rather less than usual; but its late culmination was an unusual feature. There seems to be no data available for Bering Strait and the Beaufort Sea. In the North Atlantic there was an abnormally easterly distribution of icebergs; very few bergs followed the less important westerm branch of the Labrador current that flows along the Avalon Peninsula of Newfoundland. But the total amount of ice in the Newfoundland area was about the usual.

\section{Fair isle Bird Observatory}

LyING directly between Orkney and Shetland, Fair Isle has been well known as a bird migration station since Dr. Eagle Clark began his observations there in 1905. Since the Second World War, and largely through the efforts of George Waterston, Ian Pitman and Arthur Duncan, the Fair Isle Bird Observatory Trust has been formed in order to develop the use of the island as one of Europe's premier bird observa. tories. Already a full-time director has been appointed and a certain amount of equipment installed; but much more support will be needed before the natural ornithological advantages of the island can be investigated. Copies of an attractive booklet describing the Fair Isle Bird Observatory can be obtained from 48 Castle Street, Edinburgh.

\section{Kangaroos}

THE ordinary person probably regards the kangaroo as the most characteristic of the native animals of Australia, and the Macropodidæ is the family with the largest number of species and contains the largest animals. Considerable work has been done on this group; but nevertheless the review of the family given by G. H. H. Tate (Bull. Amer. Mus. Nat. Hist., 91 ; 1948) is timely. The review falls into two parts, one on the anatomy and phylogeny, and the other on the taxonomy. It is suggested that phylogenetically two basal stocks, the subfamilies Potoroinæ and Macropodinæ, can be recognized; but the relationship between them is not clear. Some authorities have gone so far as to suggest that each has arisen inde. pendently from a phalangeroid stock. It seems clear that no division of the recent phalangerids could have given rise to either subfamily. Within the groups the author gives reasonable phylogenetic lines. To the four generally recognized subfamilies, the author adds a fifth for the reception of certain extinct species, the Palorchestinæ. He recognizes and defines 107 distinct forms falling into 22 genera. A considerable literature has grown up around the question of the specific identification of the kangaroo recorded by Captain Cook, and, after a review of this and other evidence, the author concludes that the animal in question is Macropus canguru canguru, a north-eastern subspecies, the south-eastern equivalent of which is Macropus canguru major.

\section{Radar Training Devices}

AT a meeting of the radio section of the Institution of Electrical Engineers on November 2, Mr. G. W. A. Dummer presented a paper entitled "Aids to Training - The Design of Radar Synthetic Training Devices for the R.A.F.". In this paper, the author describes how, during the War, work was conducted by the Trainer Design Group at the Telecommunications
Research Establishment, in the development of equipment used by the Royal Air Force for training operators, navigators and controllers in radar techniques. With the introduction of each new radar system, a simple synthetic trainer was designed concurrently. As operational experience was gained on the equipment, a more complex crew trainer was developed; this provided accurate presentation of a moving synthetic target or targets, and complete operational practice with a record of the trainee's errors. Approximately seventy different types of trainers were developed for the various radar systems, varying in scope from the provision of simple synthetic echoes to a complex device such as the reproduction on the ground of a complete nightfighter interception in the air. The fundamental principles necessary for the control of synthetic targets in two and three dimensions are discussed in the paper, the presentation of which was illustrated by an extended cinematograph film. With the end of the War the urgent necessity for training devices declined, and comparatively few trainers are being designed at the present time. In the discussion at the meeting, however, various speakers pointed out the need of this type of equipment for training the crews and operators of eivil aviation services.

\section{Distance of Canopus}

MR. O. R. WALKEY has investigated the distance of Canopus ( $\alpha$ Carinæ) by a new line of approach (J. Brit. Ast. Assoc., 58, No. 6 ; 1948). The results obtained for this star vary considerably, some of the derived parallaxes being more than five times those of others. Mr. Walkey approaches the problem from the secular parallax of the star, a star's proper motion being frequently a fair criterion of its distance, and the radial velocity of Canopus provides a clue in the present case. Accepting results he has obtained for the apex of the solar motion (Mon. Not. Roy. Ast. Soc., 106, No. 4; 1946) and also for the velocity of the sun, the antapex of this motion, R.A. $90 \cdot 2^{\circ}$, Dec. $-28 \cdot 7^{\circ}$, is just $24^{\circ}$ north of Canopus, and as the recessional radial velocity of the star is $20.8 \mathrm{~km}$. $/ \mathrm{sec}$., we may regard it as stationary within the velocity framework. The proper motion of Canopus in R.A. is given as $0.0020^{\mathrm{s}} \pm 0.0012^{\mathrm{s}}$ in G.C., and the large probable error in $\vec{R}$.A. should, Mr. Walkey thinks, warrant the simplicity of considering the motion in declination alone in the investigation. This is $0.017^{\prime \prime}+0.0015^{\prime \prime}$ towards the solar antapex, and applying the correction for galactic rotation it becomes $0 \cdot 0126^{\prime \prime} \pm 0 \cdot 0015^{\prime \prime}$. If this represents the crosswise reflex of the sun's motion from the antapex, the absolute parallax of Canopus is $0.0071^{\prime \prime} \pm 0.00009^{\prime \prime}$. Adopting a final parallax of $0.007^{\prime \prime}$ or a distance of 450 light-years, the absolute magnitude of the star is $-6 \cdot 6$. It is significant that this distance finds confirmation in Charlier's determination of the distance of the centre of the brighter $B$-type stars lying in Carina ( $M e d d$. Lund., Series ii, $14 ; 1916.34$; 1926). The revised and higher luminosity basis, of one magnitude brighter than that used by Charlier for the given $B$ stars, places their centre at a distance represented by a parallax of $0.0072^{\prime \prime}$.

\section{International Union of Biological Sciences}

THE programme of symposia, organised with the help of Unesco by the International Union of Biological Sciences, started in November 1947 with a symposium on trace elements in plant physiology. 
held at Rothamsted (see Nature, 161, 364; 1948). The report of this Conference is in the press at Chronica Botanica Co., Waltham, Mass. The second symposium of this series was held during June 14-19, 1948, at Utrecht; it dealt with the theoretical basis of botanical nomenclature and systematics. The full report will also be published by the Chronica Botanica Co. A third symposium was the first International Congress on the Physio-Pathology of Animal Reproduction at Milan; it lasted two days (June 21-22, 1948) and its theme was: "Interactions between Eggs and Sperm". The full report is to be published by its secretary, Prof. T. Bonadonna, Via Fratelli Bronzetti 17, Milan. A symposium on Terminology of Cytogenetics and Genetics was held at Stockholm during July 15-16, 1948. This symposium carriod further the work done at the pre-war symposium held in London during August 14-15, 1939. A committee has been formed to supervise the preparation of the full report, which probably will be published as a separate number of Bibliographia Genetica. Finally, a fifth symposium was held at Stockholm during August 5-7, 1948, which discussed the scientific foundations of an international organ. isation for combating agricultural pests. A pro. gramme for further work on the subject has been drawn up; and the report of the meeting will be published by the general secretary of the International Union, Prof. P. Vayssière, Muséum d'Histoire Naturelle, Paris.

\section{City and Guilds of London Institute}

THE report of the Council of the City and Guilds of London Institute for 1947 gives ample evidence of the Institute's growing activities. There has been a large increase in the number of students at the City and Guilds College, particularly postgraduate and research students. In the Department of Technology the total number of candidates examined was 47,807, 7,336 higher than the previous highest total of 40,471 recorded in 1939. Among the regulations and syllabuses for existing examinations which have been revised during 1947 are those of petroleum and petroleum products, electrical ongineering practice, road service work and motor-vehicle electrician's work; while among syllabuses at present being considered for introduction later into the examinations conducted by the technology department are courses in works administration subjects for craftsmen, servicing and maintenance for instrument mechanics, and courses for electrical apprentices in iron and steel and other heavy engineering work. Copies of the report may be obtained from Gresham College, Basinghall Street, London, E.C.2.

\section{Exhibition of Radiographs}

AN exhibition of industrial radiographs will be held at the spring meeting of the Industrial Radiology Group at the Institute of Physics on February 18 and 19, 1949. Entries should be suitable for showing on standard viewing lanterns (mounted prints may also be submitted) and should, wherever possible, be accompanied by photographs or samples of the specimens which they represent. A short description should accompany each entry. Intending exhibitors should apply to the Institute of Physics, 47 Belgrave Square, London, S.W.1, for entry forms.

\section{"Animals of Australia"}

THE third of the series of natural history booklets has now been published by the Glasgow Art Galleries and Museum. Like the first two of the series, "Animals of Africa" and "Animals of India", the new booklet has been written primarily as an account of the Australian habitat group, one of the large groups in the Mammal Court of the Museum. The booklet contains a simple description of the life and habits of each of the animals as well as a photograph and outline drawing which serves as a key to the display.

\section{Announcements}

THE president of the Royal Society has appointed the following vice-presidents for the ensuing year : Sir Thomas Merton, treasurer of the Royal Society ; Sir Edward Salisbury, biological secretary of the Royal Society, director of the Royal Botanic Gardens, Kew ; Sir James Chadwick, master of Gonville and Caius College, Cambridge; Prof. A. C. Hardy, Linacre professor of zoology in the University of Oxford.

Dr. H. GReinacher, professor of experimental physics in the Faculty of Sciences of the University of Berne, has been awarded the Theodor Kocher Prize by the University in recognition of his skill in experimental work, specially for the development of the 'Greinacher circuit', widely used in applied X-rays. This circuit, which was described in 1914 (Deutsch. Phys. Gesell. Verh., 16, 320; April 15, 1914), is one of the best-known circuits that combine voltage-multiplying with a constant potential.

Dr. F. A. Burchardt, of Magdalen College, has been appointed director of the Oxford University Institute of Statistics, with effect from January 1, in succession to Mr. D. G. Champernowne, now professor of statistics in the University.

Mr. A. W. Hendry has been appointed to the University readership in civil engineering tenable at King's College, University of London, as from May 1, 1949. The title of professor of chemical pathology in the University has been conferred on Dr. Jocelyn Patterson, in respect of the post held by him at Charing Cross Hospital Medical School. The degree of D.Sc. has been conferred on Mr. E. R. Leonard, an internal student.

The Langley Memorial Prize, offered by the London School of Hygiene and Tropical Medicine, and open to competition among officers, past and present, of the West African medical departments, has been awarded to Dr. D. Fitzgerald Moore for an essay entitled "Nutritional Eye Disease and Effects of Nutritional Retrobulbar Neuritis".

Trintry College, Cambridge, offers research studentships and Dominion and Colonial exhibitions every year ; the next elections will take place in July 1949. Research studentships are open to graduates of universities other than Cambridge who are not more than twenty-six years of age, although in computing his age a candidate may deduct any period of war service. The exhibitions are open to undergraduates as well as those wishing to undertake research. Applications, to be sent through the head of the candidate's university, must reach the Senior Tutor, Trinity College, Cambridge, not later than May 1, 1949.

Two Christmas Lectures, for older children, will be delivered at the Institution of Electrical Engineers by Dr. P. Dunsheath, under the general title "Electricity : a Giant Harnessed". The Lectures will be given on December 29 and 30 at 3 p.m. 